\title{
Stent placement in patients with coronary heart disease decreases plasma levels of the endogenous nitric oxide synthase inhibitor ADMA
}

\author{
ZÉNÓ AJTAY ${ }^{1 *}$, FORTUNATO SCALERA ${ }^{2 *}$, ATTILA CZIRÁKI ${ }^{1}$, IVÁN HORVÁTH ${ }^{1}$, \\ LAJOS PAPP ${ }^{1}$, ENDRE SULYOK $^{3}$, CSABA SZABO $^{4}$, JENS MARTENS-LOBENHOFFER ${ }^{2}$, \\ FRIEDEMANN AWISZUS ${ }^{5}$ and STEFANIE M. BODE-BÖGER ${ }^{2}$
}

\begin{abstract}
${ }^{1}$ Heart Institute, Faculty of Medicine, University of Pécs, Ifjúság u. 13., H-7624 Pécs, Hungary;
${ }^{2}$ Institute of Clinical Pharmacology, University Hospital, Otto-von-Guericke University, Leipziger Strasse 44, D-39120 Magdeburg, Germany; ${ }^{3}$ Institute of Health Promotion and Family Care, Faculty of Health Sciences, University of Pécs, Vörösmarty út 4, H-7621 Pécs, Hungary; ${ }^{4}$ Department of Anesthesiology, University of Texas Medical Branch, 610 Texas Avenue, Galveston, TX 77555-0833, USA; ${ }^{5}$ Department of Orthopedics, University

Hospital, Otto-von-Guericke University, Leipziger Strasse 44, D-39120 Magdeburg, Germany
\end{abstract}

Received October 30, 2008; Accepted December 5, 2008

DOI: 10.3892/ijmm_00000176

\begin{abstract}
The concentration of asymmetric dimethylarginine (ADMA), an endogenous inhibitor of nitric oxide synthase, is increased in patients with coronary heart disease (CHD). The potential effect of percutaneous coronary intervention (PCI) with stent placement on ADMA plasma level in CHD patients has not yet been investigated. Concentrations of ADMA, L-arginine, symmetric dimethylarginine (SDMA), and L-ornithine were measured in the plasma of $30 \mathrm{CHD}$ patients $24 \mathrm{~h}$ before, and $1 \mathrm{~h}, 5$ days, and 30 days following PCI with bare-metal stent or drug-eluting stent placement (stent group) and in the plasma of 20 patients without CHD who underwent angiography alone (control group). A repeated measures ANOVA revealed the significant time by group interaction for ADMA $(\mathrm{F}=12.8, \mathrm{p}<0.0001)$, SDMA $(\mathrm{F}=5.5, \mathrm{p}=0.013)$, L-ornithine $(\mathrm{F}=12.5, \mathrm{p}<0.0001)$, L-aginine $(\mathrm{F}=4.7, \mathrm{p}=0.013)$ and $\mathrm{L}$-arginine/ADMA ratio $(\mathrm{F}=7.1, \mathrm{p}<0.001)$. Post-hoc ANOVAs showed that this interaction was due to the fact that control patients without stent placement responded to the coronary angiography with a significant increase in ADMA $(\mathrm{F}=4.4, \mathrm{p}=0.009)$, SDMA $(\mathrm{F}=4.7, \mathrm{p}=0.007)$ and L-ornithine $(\mathrm{F}=28.3, \mathrm{p}<0.0001)$ levels, whereas the stent implantation
\end{abstract}

Correspondence to: Professor Endre Sulyok, Institute of Health Promotion and Family Care, Faculty of Health Sciences University of Pécs, Vörösmarty u. 4, H-7621 Pécs, Hungary

E-mail: esulyok@enternet.hu

${ }^{*}$ Contributed equally

Key words: angiography, risk factor, L-arginine, L-arginine/ asymmetrical dimethylarginine ratio independent of the stent type used significantly reduced the cardiovascular risk factor ADMA ( $F=10.8, p<0.0001)$. Thus, the current study demonstrates that in patients with CHD, PCI stent placement markedly decreases the plasma level of cardiovascular risk factor ADMA. Coronary angiography alone results in an increase of ADMA. We conclude that the stent effect on ADMA level cannot be explained by unspecific effects of the coronary angiography and is independent of the stent type used.

\section{Introduction}

Asymmetric dimethylarginine (ADMA) which is generated by protein arginine methyltransferase type I (PRMT-1) (1) and mainly metabolized by dimethylarginine dimethylaminohydrolase (DDAH) $(2,3)$ has been recognized as an endogenous, competitive inhibitor of nitric oxide synthase (NOS) $(4,5)$. ADMA accumulation due either to enhanced production or to reduced elimination limits nitric oxide (NO) production, impairs endothelial function and accelerates the progression of cardiovascular diseases. ADMA, therefore, is regarded as a marker and mediator of vascular dysfunction and it has been identified as an independent risk factor for adverse cardiovascular events including death (6-8). As traditional risk factors and new biomarkers of cardiovascular pathologies are associated with elevated ADMA concentration, ADMA is considered as a common pathway mediating the untoward vascular effects of various risk factors for atherosclerosis and related diseases (8).

During recent years particular attention was paid to explore the involvement of ADMA in the pathogenesis of coronary heart disease (CHD). Prospective clinical trials conducted in patients with stable angina pectoris, recurrent vasospastic angina or with a history of myocardial infarction provided firm evidence that plasma concentration of ADMA increased with increasing number of risk factors and elevated 
Table I. Values of the observed risk parameters in patients who underwent elective coronary angiography without diagnosis of coronary heart disease (CHD) (control group) compared to CHD patients who underwent PCI with stent placement (stent group).

\begin{tabular}{|c|c|c|c|}
\hline Variable & Control group $(n=20)$ & Stent group $(n=30)$ & p-value \\
\hline Age (years) & $59 \pm 8$ & $63 \pm 9$ & 0.146 \\
\hline Male, n (\%) & $10(53)$ & $20(67)$ & 0.345 \\
\hline Diabetes mellitus, n (\%) & $4(21)$ & $9(30)$ & 0.490 \\
\hline Smoking, n (\%) & $1(5)$ & $7(23)$ & 0.062 \\
\hline Body mass index $\left(\mathrm{kg} / \mathrm{m}^{2}\right)$ & $27.8 \pm 4.9$ & $27.5 \pm 4.0$ & 0.808 \\
\hline LDL-cholesterol (mmol/l) & $3.18 \pm 1.13$ & $2.93 \pm 1.17$ & 0.518 \\
\hline Fibrinogen $(\mathrm{g} / \mathrm{l})$ & $3.61 \pm 0.78$ & $3.45 \pm 1.17$ & 0.122 \\
\hline hsCRP (mg/l) & $3.48 \pm 3.91$ & $9.34 \pm 9.30$ & 0.030 \\
\hline Homocysteine $(\mu \mathrm{mol} / \mathrm{l})$ & $19.51 \pm 21.06$ & $15.04 \pm 6.49$ & 0.437 \\
\hline Creatinine $(\mu \mathrm{mol} / \mathrm{l})$ & $71.47 \pm 44.94$ & $97.75 \pm 28.88$ & 0.019 \\
\hline Microalbuminuria, n (\%) & 0 & $5(17)$ & - \\
\hline $\mathrm{EF}(\%)$ & $58.17 \pm 7.81$ & $50.24 \pm 11.63$ & 0.017 \\
\hline RR syst (mmHg) & $141 \pm 11$ & $136 \pm 26$ & 0.538 \\
\hline $\mathrm{RR}$ diast (mmHg) & $84 \pm 7$ & $78 \pm 11$ & 0.075 \\
\hline \multicolumn{4}{|l|}{ Treatment, n (\%) } \\
\hline Nitrate & $3(15)$ & $11(37)$ & 0.099 \\
\hline Statin & $17(89)$ & $24(80)$ & 0.366 \\
\hline ACEI & $16(84)$ & $21(70)$ & 0.246 \\
\hline ARB & 0 & $6(20)$ & - \\
\hline
\end{tabular}

Values are presented as number (relative percentages) or mean \pm SD. Risk factors were defined according to the European Society of Cardiology guidelines (10). EF, left ventricular ejection fraction; RR syst, systolic blood pressure; RR diast, diastolic blood pressure; hsCRP, high-sensitivity C-reactive protein; ACEI, angiotensin converting enzyme inhibitor; ARB, angiotensin receptor blocker.

ADMA levels were associated with significantly higher risk of developing CHD (9-11). Moreover, studies were carried out to assess the effects of medical treatment on ADMA levels in patients with acute coronary syndrome (12). Furthermore, elevated plasma ADMA concentration is an independent predictor of worse cardiovascular events in patients undergoing percutaneous coronary intervention (PCI) (13).

In the present study, we investigated the plasma concentration of ADMA in patients who underwent PCI with stent implantation. Moreover, we investigated the relationship between ADMA and L-arginine, symmetrical dimethylarginine (SDMA), and L-ornithine levels.

\section{Materials and methods}

Patients. Thirty consecutive patients with CHD were hospitalized at the Heart Institute of the Faculty of Medicine, University of Pécs, Hungary for elective coronary angiography and PCI as it was required. Twenty patients who underwent elective coronary angiography without CHD or PCI were included as control. Coronary angiography was performed because the non-invasive data suggested or proved coronary disease (Table I). The study protocol was approved by the Local Ethics Committee of the Faculty of Medicine of University of Pécs. Full informed consent was obtained from all patients before participation in the study. The investigation conforms to the principle outlined in the Declaration of Helsinki.

From the blood chemistry standard estimation of risk parameters of ischemic heart disease based on current guidelines was performed for each patient on the day they were hospitalized. During the $24 \mathrm{~h}$ before PCI or elective coronary angiography alone we drew blood from CHD patients and controls, respectively, in order to determine ADMA, SDMA, L-arginine and L-ornithine levels. These parameters were then measured again $<1 \mathrm{~h}, 5$ days and 30 days after performing the PCI or elective coronary angiography alone, respectively. During coronary angiography we determined the type and location of the culprit lesion and the percentage of the narrowing of the coronary vessel. Prior to PCI standard, combined antithrombotic treatment was administered for each patient: 300-600 mg clopidogrel, $300 \mathrm{mg}$ aspirin, and $60 \mathrm{IU} / \mathrm{kg}$ sodium-heparin. Invasive examinations were performed using a Philips BH 5000 monoplane or biplane 
Table II. Patient characteristics observed during percutaneous coronary intervention.

\begin{tabular}{|c|c|c|c|c|}
\hline $\begin{array}{l}\text { Patients } \\
(\mathrm{n}=30)\end{array}$ & $\begin{array}{l}\text { Type of } \\
\text { lesion }^{\mathrm{a}}\end{array}$ & $\begin{array}{c}\text { Stenosis } \\
(\%)\end{array}$ & Location & $\begin{array}{l}\text { No. of } \\
\text { stents }\end{array}$ \\
\hline 1 & A & 58 & $\mathrm{RCA}$ & 1 \\
\hline 2 & $\mathrm{~B}$ & 81 & LAD & 4 \\
\hline 3 & $\mathrm{C}$ & 57 & LAD-DIAG & 1 \\
\hline 4 & $\mathrm{C}$ & 100 & LAD-DIAG & 4 \\
\hline 5 & $\mathrm{C}, \mathrm{B}$ & 62 & LAD & 3 \\
\hline 6 & $\mathrm{~B}$ & 86 & $\mathrm{CX}$ & 1 \\
\hline 7 & $\mathrm{C}$ & 70 & LAD & 3 \\
\hline 8 & A & 55 & $\mathrm{CX}$ & 1 \\
\hline 9 & $\mathrm{~B}, \mathrm{~A}$ & 81 & LAD & 2 \\
\hline 10 & $\mathrm{~B}, \mathrm{C}$ & 100 & RCA & 2 \\
\hline 11 & $\mathrm{C}$ & 90 & RCA & 3 \\
\hline 12 & $\mathrm{C}$ & 95 & $\mathrm{CX}$ & 1 \\
\hline 13 & $\mathrm{C}$ & 95 & RCA & 2 \\
\hline 14 & $\mathrm{C}$ & 71 & LAD & 2 \\
\hline 15 & $\mathrm{~B}$ & 55 & LAD-DIAG & 2 \\
\hline 16 & $\mathrm{C}$ & 100 & LAD & 4 \\
\hline 17 & $\mathrm{C}$ & 95 & $\mathrm{CX}$ & 1 \\
\hline 18 & $\mathrm{~B}$ & 95 & $\mathrm{CX}$ & 1 \\
\hline 19 & $\mathrm{~B}$ & 95 & $\mathrm{CX}$ & 2 \\
\hline 20 & $\mathrm{C}$ & 52 & LAD & 1 \\
\hline 21 & $\mathrm{C}$ & 73 & CX & 1 \\
\hline 22 & $\mathrm{C}$ & 75 & $\mathrm{CX}$ & 4 \\
\hline 23 & $\mathrm{~B}$ & 82 & $\mathrm{CX}$ & 2 \\
\hline 24 & B & 62 & LAD & 1 \\
\hline 25 & A & 95 & RCA & 1 \\
\hline 26 & B & 80 & RCA & 3 \\
\hline 27 & B & 80 & LAD & 1 \\
\hline 28 & B & 85 & LAD & 3 \\
\hline 29 & B & 75 & LAD & 1 \\
\hline 30 & A & 75 & RCA & 1 \\
\hline
\end{tabular}

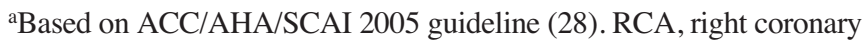
artery; LAD, left anterior descending artery; CX, circumflex artery; DIAG, diagonal branch.

system. Recordings were analysed afterwards by two welltrained invasive cardiologists with the Philips QCA software. The degree of stenosis in diameter was evaluated from two different views. Seventy-five percent stenosis in diameter of coronary vessel was considered significant. During PCI, baremetal stents (BMS, Medtronic), and drug-eluting stents (DES, Cordis) were implanted into the coronary vessels depending on the type of culprit coronary lesion, and the co-morbidity of the patients $(14,15)$ (Table II). Twenty-one patients were treated with $41 \mathrm{BMS}$, and 7 patients were treated with $13 \mathrm{DES}$, and 2 patients were treated with both 2 BMS and 3 DES.

Laboratory measurements. Fasting plasma samples obtained from the stent group and control were stored at $-70^{\circ} \mathrm{C}$ until analysis. Plasma L-arginine, SDMA, and ADMA were determined with liquid chromatography - tandem mass spectrometry
(LC-MS-MS) as previously described (16). The intra-day precision was $4.5 \%$ for arginine, 5.5\% for ADMA, and 3.9\% for SDMA; the inter-day precision was $4.7 \%$ for arginine, $7.7 \%$ for ADMA, and $4.9 \%$ for SDMA. For the determination of L-ornithine concentration we adopted the LC-MS-MS method published recently by our group (17). The intra-day and inter-day relative standard deviations were $1.1 \%$ and $3.5 \%$, respectively. The routine biochemical parameters were measured by using standard laboratory procedures.

Statistical analysis. Data are presented as mean value \pm SEM, with sample size (n) being indicated for each reported value. A value of $\mathrm{p}<0.05$ was considered statistically significant. t-tests were used to compare coronary risk parameters of the stent group with control. Repeated measures ANOVA with intrasubject factor time (baseline, 1 h, 5 days and 30 days) and intersubject factor group (stent vs. control) was performed for L-arginine, ADMA, SDMA, and L-ornithine and L-arginine/ ADMA ratio. Greenhouse-Geisser correction was used where necessary to account for non-sphericity of the data.

\section{Results}

As shown in Table I, CHD patients who underwent PCI with stent placement (stent group) had a significant increase of hsCRP and creatinine and a decrease of EF-values compared to patients who underwent elective coronary angiography without diagnosis of CHD (control group). Furthermore, the patients in the stent group had significantly elevated plasma concentrations of ADMA, SDMA and L-ornithine compared to control group, whereas L-arginine plasma level and L-arginine/ ADMA ratio were markedly decreased at baseline (Table III and Fig. 1).

Moreover, the observed risk parameter values (14), ADMA, L-arginine, SDMA and L-ornithine plasma level and L-arginine/ ADMA ratio at baseline were not significantly different between patients in the stent group in whom BMS or DES has been implanted (data not shown).

As shown in Fig. 1A, ADMA decreased dramatically immediately after stent placement and remained decreased even 30 days after intervention. On the other hand, in the control group ADMA increased throughout the observation period, even if the elevated ADMA levels of the stent group were not reached. The repeated measures ANOVA indicated a significant group by time interaction for ADMA ( $\mathrm{F}=12.8$, $\mathrm{p}<0.0001)$. Post-hoc ANOVAs with factor time were performed for each group separately to further analyze the interaction. The stent group showed a significant decrease of ADMA ( $\mathrm{F}=10.8, \mathrm{p}<0.0001)$. On the other hand, the control group showed a statistically significant increase of ADMA $(\mathrm{F}=4.4, \mathrm{p}=0.009)$.

As shown in Fig. 1B, L-arginine levels in the stent group were rather low at baseline, but showed an increase after stent placement and remained elevated throughout 30 days. The control group had normal L-arginine plasma levels at baseline that increased 5 days after coronary angiography. The repeated measures ANOVA indicated a significant group by time interaction for $\mathrm{L}$-arginine $(\mathrm{F}=4.7, \mathrm{p}=0.013)$ due to the fact that the L-arginine increase was much more marked in the stent group. Nonetheless post-hoc ANOVAs with factor 
Table III. ADMA, L-arginine, SDMA, and L-ornithine concentrations and L-arginine/ADMA ratio in CHD patients who underwent percutaneous coronary intervention (PCI) with stent placement (stent group) compared to patients who underwent elective coronary angiography without CHD (control group).

\begin{tabular}{|c|c|c|c|c|c|c|c|c|}
\hline \multirow[b]{2}{*}{ Variable } & \multicolumn{4}{|c|}{ Control group $(n=20)$} & \multicolumn{4}{|c|}{ Stent group $(n=30)$} \\
\hline & Baseline & $1 \mathrm{~h}$ & 5 days & 30 days & Baseline & $1 \mathrm{~h}$ & 5 days & 30 days \\
\hline $\operatorname{ADMA}(\mu \mathrm{M} / 1)$ & $0.46 \pm 0.03$ & $0.48 \pm 0.02$ & $0.48 \pm 0.02$ & $0.51 \pm 0.03$ & $0.59 \pm 0.02$ & $0.54 \pm 0.02$ & $0.53 \pm 0.02$ & $0.54 \pm 0.02$ \\
\hline $\mathrm{L}$-arginine $(\mu \mathrm{M} / \mathrm{l})$ & $70.7 \pm 4.1$ & $63.9 \pm 4.1$ & $78.8 \pm 5.9$ & $64.7 \pm 5.1$ & $35.9 \pm 4.2$ & $51.7 \pm 4.0$ & $60.8 \pm 4.6$ & $63.5 \pm 4.9$ \\
\hline $\begin{array}{l}\text { L-arginine/ } \\
\text { ADMA ratio }\end{array}$ & $157 \pm 10.5$ & $134 \pm 7.1$ & $165 \pm 11.6$ & $124 \pm 9.1$ & $64.3 \pm 7.9$ & $100 \pm 8.4$ & $116 \pm 9.1$ & $120 \pm 9.3$ \\
\hline SDMA $(\mu \mathrm{M} / \mathrm{l})$ & $0.43 \pm 0.02$ & $0.43 \pm 0.02$ & $0.48 \pm 0.03$ & $0.47 \pm 0.02$ & $0.66 \pm 0.04$ & $0.68 \pm 0.05$ & $0.59 \pm 0.03$ & $0.67 \pm 0.03$ \\
\hline L-ornithine $(\mu \mathrm{M} / \mathrm{l})$ & $62.6 \pm 4.5$ & $57 \pm 3.9$ & $78.6 \pm 5.7$ & $101 \pm 6.1$ & $157 \pm 12$ & $99.2 \pm 9.5$ & $117 \pm 8.3$ & $105 \pm 5.7$ \\
\hline
\end{tabular}

ADMA, asymmetric dimethylarginine; SDMA, symmetric dimethylarginine.

time showed significant increases of L-arginine in both groups $(\mathrm{F}=6.7, \mathrm{p}=0.001$ in the stent group, and $\mathrm{F}=5.3, \mathrm{p}=0.004$ in the control group).

The L-arginine/ADMA ratio (Fig. 1C) increased in the stent group coming from a low baseline level, whereas in the control group the time course was similar to the L-arginine course. The repeated measures ANOVA indicated a significant group by time interaction for the L-arginine/ADMA ratio $(\mathrm{F}=7.1, \mathrm{p}<0.001)$. The post-hoc ANOVA revealed a significant increase in the stent group $(\mathrm{F}=8.3, \mathrm{p}<0.0001)$.

SDMA appears to decrease in the stent group whereas SDMA appears to increase in the control group (Fig. 1D), especially 5 and 30 days after intervention. The time courses were significantly different (group by time interaction for SDMA F 5.5, $\mathrm{p}=0.013$ ). The post-hoc ANOVAs revealed that the SDMA increase observed in the control group was statistically significant $(\mathrm{F}=4.7, \mathrm{p}=0.007)$ whereas the SDMA decrease in the stent group showed only a statistical trend $(\mathrm{F}=3.5, \mathrm{p}=0.063)$ due to the larger variance in the stent group.

Finally, L-ornithine (Fig. 1E) behaved similarly to ADMA (significant group by time interaction $\mathrm{F}=12.5, \mathrm{p}<0.0001$ ) with a significant increase in the control group $(\mathrm{F}=28.3, \mathrm{p}<0.0001)$ and a significant decrease from baseline in the stent group $(\mathrm{F}=9.1, \mathrm{p}<0.0001)$.

Moreover, the levels of ADMA, SDMA, L-arginine and Lornithine during the course of the study did not reach significant difference between patients in the stent group in whom BMS or DES has been implanted (data not shown).

Interestingly, we found no association between plasma ADMA levels and other cardiovascular risk factors including LDL-cholesterol, fibrinogen, hsCPR, homocysteine, blood pressure and BMI. Moreover, there was no relationship of ADMA levels to the severity of coronary lesion. Our failure to detect such association may be attributed to the relative small samples size of our study population. However, the L-arginine level showed a highly significant inverse relationship to L-ornithine level at baseline in the stent group $(r=-0.562$, $\mathrm{p}<0.0001)$. In the control group there was no relationship between L-ornithine and L-arginine $(r=0.005, \mathrm{p}=0.96)$.
ADMA showed a direct relationship to L-ornithine ( $\mathrm{r}=0.71, \mathrm{p}=0.0001)$ when pooling data pairs from all 4 time points, showing that $50 \%$ of the variance of ADMA in the stent group could be explained by measurement of Lornithine (Fig. 2). In the control group there was a much weaker correlation with $\mathrm{r}=0.37, \mathrm{p}=0.001$.

\section{Discussion}

The present study provides for the first time evidence that restoration of coronary circulation by stent placement in patients with CHD induces a rapid and sustained decrease in the level of the new cardiovascular risk factor ADMA that is maintained during the 30 days follow-up period after stenting independent of the stent type used. Furthermore, L-ornithine shows a significant decrease after stent placement. In contrast, the plasma concentration of L-arginine increases significantly contributing to a substantial rise of L-arginine/ADMA ratio that remained at this high level until the end of the study. This phenomenon may increase the activity of endothelial NOS which, in turn, may restore the NO formation rates at physiological levels $(18,19)$ to promote the revascularization process (20). Clinically, the revascularization procedure improves the general condition, the indices of cardiac status including cardiac output, ejection fraction and myocardial contractility as well as the short- and long-term outcomes $(21,22)$.

Interestingly, the control group showed statistically significant increase of ADMA, SDMA and L-ornithine after coronary angiography presumably due to the stress situation of a normal coronary angiography with for example contrast medium application. The stent implementation does not only overcome this expected ADMA increase, but further leads to a drastic reduction of ADMA and L-ornithine levels.

Previous studies have demonstrated that intramural administration of L-arginine reduced neointimal hyperplasia after stent implantation in patients with native coronary artery disease (18). Moreover, the elevated plasma concentration of ADMA appears to be an independent predictor of subsequent major adverse cardiovascular outcome after PCI (13). 
A

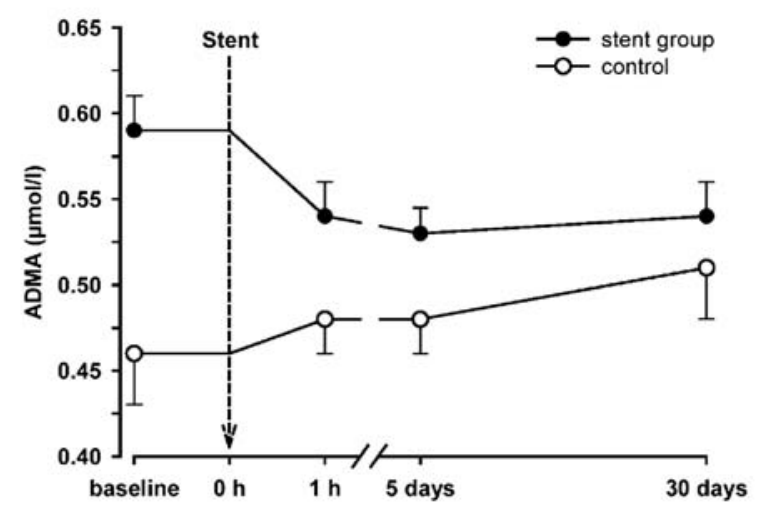

C

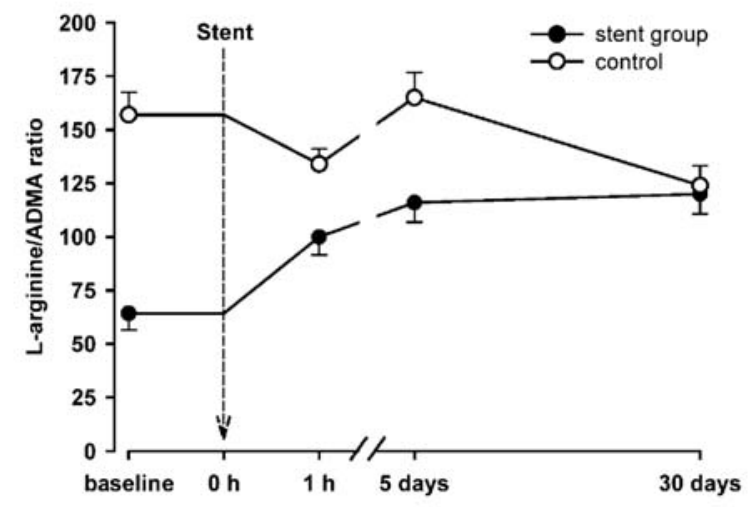

E
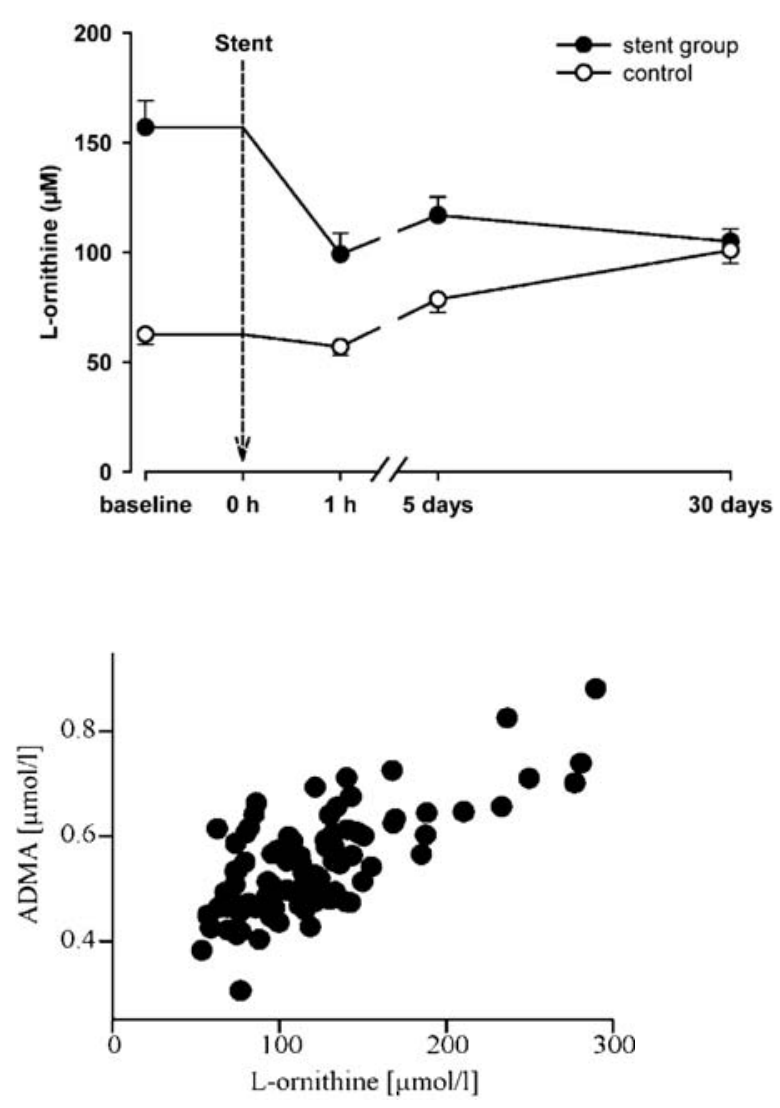

Figure 2. Relationship between ADMA and L-ornithine concentration in plasma of patients with CHD with stent implementation pooled across all four time points. $\mathrm{r}=0.71, \mathrm{p}<0.0001$; ADMA, asymmetric dimethylarginine.
B

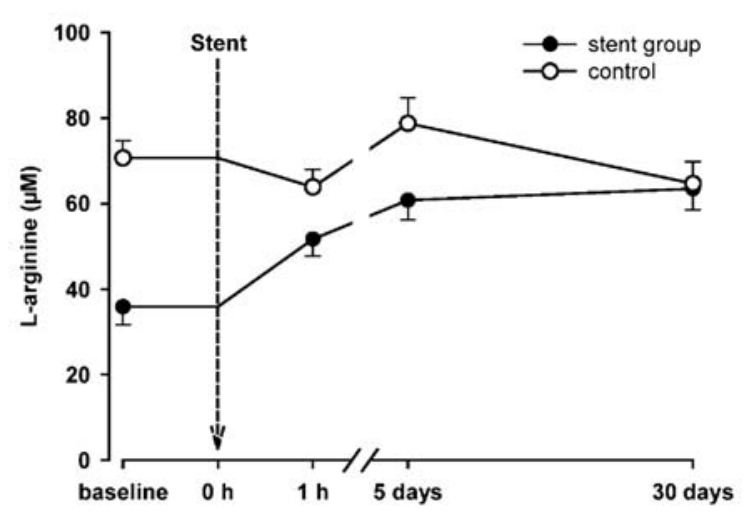

D

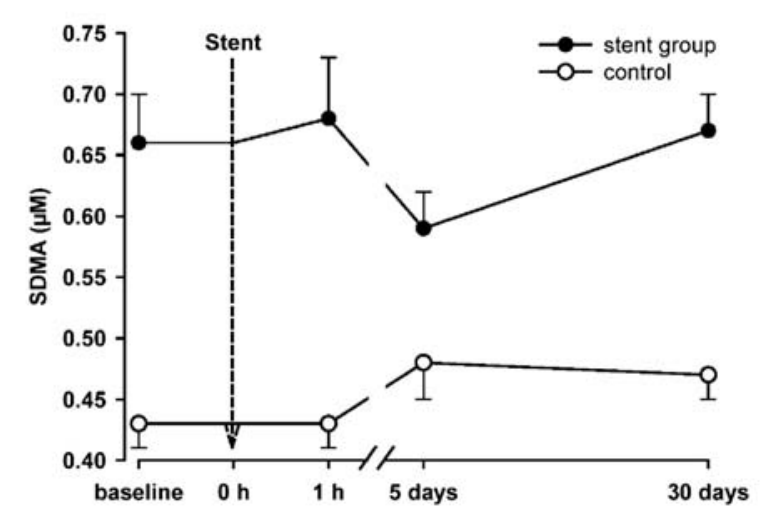

Figure 1. The response pattern of plasma ADMA (A), and L-arginine (B) concentration, and L-arginine/ADMA ratio (C), SDMA (D) and L-ornithine (E) concentration to stent placement in CHD patients (stent group) and to coronary angiography alone in patients without CHD (control). ADMA, asymmetric dimethylarginine; SDMA, symmetric dimethylarginine.

Stent implantation causes, amongst others, hemodynamic changes including wall shear stress (WSS). In 20 patients, that received at random one sirolimus-eluting stent and one BMS, WSS at 6 months follow-up remains normal in the sirolismus group but is elevated in the metal group (23). Moreover, WSS depends on the regional vascular geometry (24). WSS is the tangential drag force produced by flowing blood on the endothelial surface. It has been suggested that in native arteries of humans, regions with pathologically low endothelial shear stress (ESS) develop progressive atherosclerosis, regions with physiological ESS remained quiescent, and regions with increased ESS did not exhibit plaque progression. In stented portions of artery, there was evidence of an increase in ESS at all levels of baseline ESS (25). 
Exposure of human endothelial cells to mild or moderate shear stress enhances gene expression of PRMT-1 and the release of ADMA via activation of the NF- $\mathrm{KB}$ pathway. Shear stress at higher magnitude, however, facilitates the degradation of ADMA via enhancement of DDAH activity and reduces ADMA concentration to baseline (26). Interestingly, the activity of the enzymes involved in the formation and degradation of ADMA such as PRMT-1 and DDAH are regulated in a redox-sensitive fashion (27). Thus, oxidative stress enhances the activity of PRMT-1 and inhibits the activity of DDAH leading to increased ADMA concentration. Under those conditions, ADMA could inhibit eNOS activity and/or even uncouple the enzyme, which would further increase oxidative stress (28). In contrast, reduced oxidative stress enhances the activity of DDAH (29), which might be responsible for the decreased ADMA plasma levels observed in our study after stenting. Recently, it has been reported that activity of xanthine oxidase, an oxidant enzyme, increases significantly immediately after stent implantation, followed by a significant decrease after $6 \mathrm{~h}$ and reaching the minimum of the activity after $24 \mathrm{~h}$ in plasma of 22 patients with coronary artery disease (30). In contrast, the activity of the antioxidant enzyme catalase increases significantly $24 \mathrm{~h}$ after stent implementation. In our study, we observed a decrease of ADMA plasma levels as early as $1 \mathrm{~h}$ after stenting. If the decreased oxidative stress upregulated the activity of DDAH $24 \mathrm{~h}$ after stent placement, which mechanisms could be responsible for the decreased ADMA plasma levels $1 \mathrm{~h}$ after stenting?

ADMA as L-arginine analogue shares the same transport system with other cationic amino acids (CAAs) such as L-arginine, L-lysine or L-ornithine $(31,32)$. In most nonepithelial cells, members of the cationic amino acid transport (CAT) family mediating sodium independent $\mathrm{y}^{+}$system activity seem to be the major entry pathway for CAAs $(33,34)$. A number of these transporters work much better in the exchange than in the uniport mode. Cells expressing these transporters will therefore be readily depleted of intracellular L-arginine only when another CAA is provided at the extracellular side. Various stimuli including shear stress regulate CAT. It has been reported that shear stress affects the kinetic of L-arginine transport without affecting the transport capacity for neutral amino acids in endothelial cells (35).

In the present study, we found a change in plasma levels of ADMA, L-arginine and L-ornithine in the stent group. The plasma levels of ADMA and L-ornithine decreased, whereas the concentrations of L-arginine increased significantly during the 30-day follow-up period after stenting. Plasma levels of L-arginine were inversely correlated with L-ornithine levels. In contrast, ADMA showed a direct relationship to L-ornithine in the stent group. In the control group, plasma levels of L-arginine were uncorrelated with L-ornithine, and the direct relationship of ADMA with L-ornithine was much weaker. This indicates that stent implementation presumably increases ADMA and L-ornithine transport into the cell whereas L-arginine transport out of the cell seems to be enhanced.

In contrast to ADMA, SDMA does not interfere directly with NOS activity (5), and is synthesized by PRMT-II (36). SDMA shares the same CAT system with ADMA $(31,32)$.
We showed no consistent changes in SDMA during the entire follow-up. Since SDMA is not metabolized by DDAH (37), the plasma levels of SDMA returned to initial value after 30 days, which could be associated with a non-significant decrease of L-ornithine plasma levels between 5 days and 30 days. A further explanation could be the decreased renal function due to the application of contrast medium during stent implantation leading to an increase of SDMA and the consecutive decrease of SDMA after 5 days. In the control group where the effect of contrast medium is not masked we found a significant increase of SDMA, which remained elevated up to 30 days.

Based on our data we suggest that in patients with CHD, stent placement may decrease the level of the new cardiovascular risk factor ADMA. We speculate that changes in CAT and in DDAH activity may be responsible for the observed effect.

\section{Acknowledgements}

The study was supported by grant ETT No. 50035 .

\section{References}

1. Böger RH, Sydow K, Borlak J, et al: LDL cholesterol upregulates synthesis of asymmetrical dimethylarginine in human endothelial cells: Involvement of S-adenosylmethioninedependent methyltransferases. Circ Res 87: 99-105, 2000.

2. Ogawa T, Kimoto M and Sasaoka K: Purification and properties of a new enzyme, NG, NG-dimethylarginine dimethylaminohydrolase, from rat kidney. J Biol Chem 264: 10205-10209, 1989.

3. Ueda S, Kato S, Matsuoka H, Kimoto M, Okuda S, Morimatsu M and Imaizumi T: Regulation of cytokine-induced nitric oxide synthesis by asymmetric dimethylarginine: Role of dimethylarginine dimethylaminohydrolase. Circ Res 92: 226-233, 2003.

4. Matsuoka H, Itoh S, Kimoto M, et al: Asymmetrical dimethylarginine, an endogenous nitric oxide synthase inhibtor, in experimental hypertension. Hypertension 29: 242-247, 1997.

5. Vallance P, Leone A, Calver A, Collier J and Moncada S: Accumulation of an endogenous inhibtor of nitric oxide synthesis in chronic renal failure. Lancet 339: 572-575, 1992.

6. Böger RH, Bode-Böger SM, Szuba A, Tsao PS, Chan JR, Tangphao O, Blaschke TF and Cooke JP: Asymmetric dimethylarginine (ADMA): A novel risk factor for endothelial dysfunction - Its role in hypercholesterolemia. Circulation 98: 1842-1847, 1998.

7. Cooke JP: Asymmetric dimethylarginine - the Über marker? Circulation 109: 1813-1819, 2004.

8. Kielstein JT and Zoccali C: Asymmetric dimethylarginine: A cardiovascular risk factor and a uremic toxin coming of age? Am J Kidney Dis 46: 186-202, 2005.

9. Hori T, Matsubara T, Ishibashi T, et al: Significance of asymmetric dimethylarginine (ADMA) concentrations during coronary circulation in patients with vasopastic angina. Circ J 67: 305-311, 2003

10. Schnabel R, Blankenberg S, Lubos E, et al: Asymmetric dimethylarginine and the risk of cardiovascular events and death in patients with coronary artery disease. Results from the AtheroGene study. Circ Res 97: E53-E59, 2005.

11. Valkonen VP, Päivä H, Salonen JT, Lakka TA, Lehtimäki T, Laakso $J$ and Laaksonen R: Risk of acute coronary events and serum concentration of asymmetrical dimethylarginine. Lancet 358: 2127-2128, 2001

12. Bae SW, Stühlinger MC, Yoo HS, et al: Plasma asymmetric dimethylarginine concentrations in newly diagnosed patients with acute myocardial infarction or unstable angina pectoris during two weeks of medical treatment. Am J Cardiol 95: 729-733, 2005.

13. Lu TM, Ding YA, Lin SJ, Lee WS and Tai HC: Plasma levels of asymmetric dimethylarginine and adverse cardiovascular events after percutaneous coronary intervention. Eur Heart J 24: 1912-1919, 2003. 
14. De Backer G, Ambrosioni E, Borch-Johnsen K, et al: European guidelines on cardiovascular disease prevention in clinical practice. Third joint task force of European and other societies on cardiovascular disease prevention in clinical practice. Eur Heart J 24: 1601-1610, 2003

15. Smith SC Jr, Feldman TE, Hirshfeld JW Jr, et al: ACC/AHA/ SCAI 2005 guideline update for precutaneous coronary intervention - summary article: a report of the American College of Cardiology/American Heart Association Task Force on Practice Guidelines (ACC/AHA/SCAI Writing Committee to Update the 2001 Guidelines for Percutaneous Coronary Intervention). Catheter Cardiovasc Interv 67: 87-112, 2006.

16. Martens-Lobenhoffer J and Bode-Böger SM: Fast and efficient determination of arginine, symmetric dimethylarginine, and asymmetric dimethylarginine in biological fluids by hydrophilicinteraction liquid chromatography-electrospray tandem mass spectrometry. Clin Chem 42: 488-493, 2006.

17. Martens-Lobenhoffer J, Postel S, Tröger U and Bode-Böger SM: Determination of ornithine, in human plasma by hydrophilicinteraction chromatography-tandem mass spectrometry. J Chromatogr B 855: 271-275, 2007.

18. Suzuki T, Hayase M, Hibi K, et al: Effect of local delivery of L-arginine on in-stent restenosis in human. Am J Cardiol 89: 363-367, 2002.

19. Bode-Böger SM, Scalera F and Ignarro LJ: The L-arginine paradox: importance of the L-arginine/asymmetrical dimethylarginine ratio. Pharmacol Ther 114: 295-306, 2007.

20. Luque Contreras D, Vagas Robles H, Romo E, Rios A and Escalante B: The role of nitric oxide in the post-ischemic revascularization process. Pharmacol Ther 112: 553-563, 2006.

21. Stone GW, Brodie BR, Griffin JJ, et al: Prospective, multicenter study of the safety and feasibility of primary stenting in acute myocardial infarction: in-hospital and 30-day results of the PAMI stent pilot trial. The Primary Angioplasty in Myocardial Infarction (PAMI) Stent Pilot Trial Investigators. J Am Coll Cardiol 31: 23-30, 1998.

22. The GUSTO Angiographic Investigators. The effects of tissue plasminogen activator, streptokinase, or both on coronary artery patency, ventricular function, and survival after acute myocardial infarction. N Engl J Med 329: 1615-1622, 1993.

23. van't Veer M, Pijls NHJ, Aarnoudse W, Koolen JJ and van de Vosse FN: Evaluation of the haemodynamic characteristics of drug-eluting stents at implantation and at follow-up. Eur Heart J 27: 1811-1817, 2006

24. LaDisa JF Jr, Olson LE, Douglas HA, Warltier DC, Kersten JR and Pagel PS: Alterations in regional vascular geometry produced by theoretical stent implantation influence distributions of wall shear stress: analysis of a curved coronary artery using 3D computational fluid dynamic modeling. Biomed Eng Online 5: 40,2006
25. Stone PH, Coskun AU, Kinlay S, et al: Effect of endothelial shear stress on the progression of coronary artery disease, vascular remodeling, and in-stent restenosis in humans. In vivo 6-months follow-up study. Circulation 108: 438-444, 2003.

26. Osanai T, Saitoh M, Sasak S, Tomita H, Matsunaga T and Okumura K: Effect of shear stress on asymmetric dimethylarginine release from vascular endothelial cells. Hypertension 42: $985-990,2003$

27. Sydow K and Münzel T: ADMA and oxidative stress. Atherosclerosis 4 (Suppl): 41-51, 2003.

28. Scalera F, Martens-Lobenhoffer J, Täger M, Bukowska A, Lendeckel U and Bode-Böger SM: Effect of L-arginine on asymmetric dimethylarginine (ADMA) or homocysteineaccelerated endothelial cell aging. Biochem Biophy Res Commun 345: 1075-1082, 2006.

29. Scalera F, Borlak J, Beckmann B, Martens-Lobenhoffer J, Thum T, Täger M and Bode-Böger SM: Endogenous nitric oxide synthesis inhibitor asymmetric dimethylarginine accelerated endothelial cell senescence. Arterioscler Thromb Vasc Biol 24: 1816-1822, 2004.

30. Apostolovic S, Perisc Z, Cosic I and Tomasevic M: Oxidant stress after coronary stent implementation. Facta Universitatis Series. Med Biol 13: 78-83, 2007.

31. Bogle RG, MacAllister RJ, Whitley GS and Vallance P: Induction of NG-monomethyl-L-arginine uptake: a mechanism for differential inhibition of NO synthases? Am J Physiol 269: C750-C756, 1995.

32. Closs EI, Basha FZ, Habermeier A and Förstermann U: Interference of L-arginine analogues with L-arginine transport mediated by the y+ carrier hCAT-2B. Nitric Oxide 1: 65-73, 1997.

33. Closs EI, Simon A, Vékony N and Rotmann A: Plasma membrane transporters for arginine. J Nutr 134: S2752-S2759, 2004.

34. Mann GE, Yudilevich DL and Sobrevia L: Regulation of amino acid and glucose transporters in endothelial and smooth muscle cells. Physiol Rev 83: 183-252, 2003.

35. Posch K, Schmidt K and Graier WF: Selective stimulation of L-arginine uptake contributes to shear stress-induced formation of nitric oxide. Life Sci 64: 663-670, 1999.

36. Lee JH, Cook JR, Yang ZH, et al: PRMT7, a new protein arginine methyltransferase that synthetizes symmetric dimethylarginine. J Biol Chem 280: 3656-3664, 2005.

37. Leiper JM, Santa Maria J, Chubb A, MacAllister RJ, Charles IG, Whitley GS and Vallance P: Identification of two human dimethylarginine dimethylaminohydrolases with distinct tissue distributions and homology with microbial arginine deaminases. Biochem J 343: 209-214, 1999. 